\title{
Metabolic and neuroprotective effects of dapagliflozin and liraglutide in diabetic mice
}

\author{
Paul Millar', Nupur Pathak', Vadivel Parthsarathy', Anthony J Bjourson², \\ Maurice O'Kane ${ }^{2,3}$, Varun Pathak', R Charlotte Moffett' ${ }^{1}$, Peter R Flatt' ${ }^{1}$ and Victor A Gault' \\ ISAAD Centre for Pharmacy and Diabetes, School of Biomedical Sciences, University of Ulster, Northern Ireland, UK \\ ${ }^{2}$ Northern Ireland Centre for Stratified Medicine, University of Ulster, C-TRIC Building, \\ Altnagelvin Hospital, Northern Ireland, UK \\ ${ }^{3}$ Clinical Chemistry Laboratory, Western Health and Social Care Trust, Altnagelvin Hospital, Northern Ireland, UK
}

Correspondence should be addressed to V A Gault

Email

va.gault@ulster.ac.uk

\begin{abstract}
This study assessed the metabolic and neuroprotective actions of the sodium glucose cotransporter-2 inhibitor dapagliflozin in combination with the GLP-1 agonist liraglutide in dietary-induced diabetic mice. Mice administered low-dose streptozotocin (STZ) on a high-fat diet received dapagliflozin, liraglutide, dapagliflozin-plus-liraglutide (DAPA-Lira) or vehicle once-daily over 28 days. Energy intake, body weight, glucose and insulin concentrations were measured at regular intervals. Glucose tolerance, insulin sensitivity, hormone and biochemical analysis, dual-energy X-ray absorptiometry densitometry, novel object recognition, islet and brain histology were examined. Oncedaily administration of DAPA-Lira resulted in significant decreases in body weight, fat mass, glucose and insulin concentrations, despite no change in energy intake. Similar beneficial metabolic improvements were observed regarding glucose tolerance, insulin sensitivity, HOMA-IR, HOMA- $\beta$, HbA1c and triglycerides. Plasma glucagon, GLP-1 and IL-6 levels were increased and corticosterone concentrations decreased. DAPA-Lira treatment decreased alpha cell area and increased insulin content compared to dapagliflozin monotherapy. Recognition memory was significantly improved in all treatment groups. Brain histology demonstrated increased staining for doublecortin (number of immature neurons) in dentate gyrus and synaptophysin (synaptic density) in stratum oriens and stratum pyramidale. These data demonstrate that combination therapy of dapagliflozin and liraglutide exerts beneficial metabolic and neuroprotective effects in diet-induced diabetic mice. Our results highlight important personalised approach in utilising liraglutide in combination with dapagliflozin, instead of either agent alone, for further clinical evaluation in treatment of diabetes and associated neurodegenerative disorders.
\end{abstract}
Key Words
- dapagliflozin
- diabetes
- GLP-1
- glucagon
- liraglutide

\section{Introduction}

Type 2 diabetes mellitus (T2DM) is a metabolic disorder that arises due to a complex array of molecular defects manifesting in dysregulated insulin secretion, impaired insulin action or both. Since the pathophysiology of T2DM is multifaceted and involves a range of biochemical mechanisms, there is no single therapy that can effectively 
manage all aspects of the disorder (Zaccardi et al. 2016). Moreover, as T2DM and obesity levels are increasing at an alarming rate, more effective therapies and innovative treatment strategies are urgently needed to control glycaemia, reduce body weight and decrease the risk of microvascular and macrovascular complications (da Rocha Fernandes et al. 2016). The previous two decades have witnessed a surge in the number of new drug classes such as glucagon-like peptide-1 (GLP-1) agonists, dipeptidylpeptidase-4 (DPP4) inhibitors and sodium glucose cotransporter-2 (SGLT2) inhibitors (Bailey et al. 2016). Although these agents may be used as monotherapies, it is becoming increasingly apparent that successful and cost-effective management of T2DM requires the development of safe combination therapies with distinct and complementary mechanisms of action.

The kidneys play a pivotal role in regulating glucose homeostasis as most of the glucose filtered by the glomerulus is reabsorbed (Gerich et al. 2001). In healthy subjects, the high capacity, low-affinity SGLT2, reabsorbs approximately $90 \%$ of glucose in S1 segment of proximal tubules (Hediger \& Rhoads 1994, Han et al. 2008). Under conditions of chronic hyperglycaemic, SGLT2 is upregulated, and this enhances glucose reabsorption and worsens glycaemia (Rahmoune et al. 2005). Dapagliflozin, a highly selective and potent oral inhibitor of SGLT2, reduces reabsorption of filtered glucose leading to increased glucosuria and improvement in glycaemic control (Vivian 2015). Although actions of dapagliflozin appear to be independent of insulin secretion, dapagliflozin improves insulin sensitivity, most likely as a result of sustained reduction in hyperglycaemia, alleviation of glucose toxicity and weight reduction through enhanced caloric loss (Macdonald et al. 2010, Mudaliar et al. 2014, Merovci et al. 2015, Millar et al. 2016). Beneficial actions of dapagliflozin are, to some extent, limited by unrestrained hepatic glucose production (Bonner et al. 2015). Thus, inhibition of hepatic glucose output by stimulation of insulin secretion as well as inhibition of glucagon secretion may significantly enhance therapeutic efficacy of SGLT2 inhibition.

GLP-1 agonists are well established as effective agents to treat patients with T2DM due to a range of beneficial actions including weight loss, induction of satiety, inhibition of gastric emptying, stimulation of insulin secretion and inhibition of alpha cell function (Bailey et al. 2016). In addition, GLP-1 agonists exert effects at other extra pancreatic sites (Renner et al. 2016), with notable neuroprotective actions in animal models of diabetes-obesity, Alzheimer's disease (AD) and Parkinson's disease (PD) (Ashraghi et al. 2016, Tramutola et al. 2017). Liraglutide (Victoza) is a highly effective long-acting GLP-1 agonist that shares $97 \%$ sequence homology with human GLP-1 (Knudsen et al. 2000). Structural modifications include amino acid substitution of Lys ${ }^{34}$ with Arg, and addition of lipophilic $\mathrm{C}_{16}$ acyl moiety at position 26 via gamma-glutamyl linker (Madsen et al. 2007). These structural changes provide liraglutide with enhanced pharmacokinetic profile and significantly prolonged halflife, thus facilitating once-daily injection (Agersø et al. 2002). This prolonged bioactivity has been attributed to non-covalent reversible albumin binding, ability of liraglutide to self-aggregate and form heptamers in solution and stability to the enzyme DPP4 (Knudsen et al. 2000, Madsen et al. 2007, Li et al. 2016).

Given the need for more personalised treatment strategies for patients with T2DM and the unique mechanism of action of dapagliflozin and liraglutide, we hypothesised that combining both drugs would provide additive metabolic and neuroprotective outcomes. We chose to administer a GLP-1 agonist rather than DPP-4 inhibitor as DPP-4 inhibitors act to prevent the degradation of a number of regulatory peptides including GLP-1 (Bailey et al. 2016). As such, HF mice on background low-dose STZ were treated with dapagliflozin or liraglutide as monotherapy and combination therapy for 28 days. Effects on glucose tolerance, insulin sensitivity, body weight, hormones, memory and learning, islet and brain histology were assessed.

\section{Materials and methods}

\section{Animals}

Male NIH Swiss mice (aged 8-10 weeks) purchased from Harlan (Oxon, UK) were kept at $22 \pm 2^{\circ} \mathrm{C}$ with $12: 12$-h light/darkness cycle. Mice had free access to high-fat diet (45\% AFE Fat; Product Code 824053; Special Diet Services, Witham, UK; total energy $26.15 \mathrm{~kJ} / \mathrm{g}$ ). An additional group of mice had free access to standard rodent chow (Teklad Global 18\% Protein Rodent Diet; Product Code 2018S; Harlan; total energy $13.0 \mathrm{~kJ} / \mathrm{g}$ ). All animals had free access to drinking water and no adverse effects were observed during the entire experimental study. All experiments were performed according to the Principles of Laboratory Animal Care (NIH publication no. 86-23, revised 1985) and UK Home Office Regulations (UK Animals Scientific Procedures Act 1986). 


\section{Experimental design}

Mice commenced high-fat diet on day -28 and subsequently received STZ (Sigma-Aldrich) prepared in sodium citrate buffer $(\mathrm{pH} 4.5)$ on day $-14(50 \mathrm{mg} / \mathrm{kg}$; i.p.) and day $-7(50 \mathrm{mg} / \mathrm{kg}$; i.p.). Mice that displayed a blood glucose concentration greater than $13 \mathrm{mmol} / \mathrm{L}$ were recruited into the study. On day 0 , mice commenced drug treatments for 28 days as follows: Group 1 (HF control) - high-fat mice administered saline vehicle (0.9\%wt/vol; p.o.; o.d.); Group 2 (dapagliflozin) - highfat mice administered dapagliflozin $(1 \mathrm{mg} / \mathrm{kg}$; p.o.; o.d.; Selleck Chemicals; Stratech Scientific Ltd., Suffolk, UK; Catalog number S1548-SEL); Group 3 (DAPA-Lira) high-fat mice administered dapagliflozin $(1 \mathrm{mg} / \mathrm{kg}$; p.o.; o.d.) plus liraglutide $(25 \mathrm{nmol} / \mathrm{kg}$; i.p.; o.d.; GL Biochem Ltd., Shanghai, China); Group 4 (Lira) - high-fat mice administered liraglutide ( $25 \mathrm{nmol} / \mathrm{kg}$; i.p.; o.d.); Group 5 (lean control) - lean mice administered saline vehicle (0.9\% wt/vol; p.o.; o.d.). All treatments administered at 14:00 $\mathrm{h}$ and mice remained on respective diet for study duration. The rationale for choosing $1 \mathrm{mg} / \mathrm{kg}$ dapagliflozin (p.o.) and $25 \mathrm{nmol} / \mathrm{kg}$ liraglutide (i.p.) in this study was based on previously published literature (Moffett et al. 2014, Millar et al. 2016). Energy intake, body weight, glucose and insulin concentrations were measured every 3-4 days. At the end of the study, glucose tolerance $(18 \mathrm{mmol} / \mathrm{kg}$; p.o.; at 10:00 $\mathrm{h}$ in $12 \mathrm{~h}$-fasted mice), insulin sensitivity ( $25 \mathrm{U} / \mathrm{kg}$ bovine insulin; i.p.; at 10:00 $\mathrm{h}$ in nonfasted mice), novel object recognition task, dual-energy X-ray absorptiometry (DEXA) scanning, lipids, hormones/ biomarkers, islet and brain histology were performed.

\section{Biochemical and DEXA analyses}

Blood samples were collected as indicated in figures from tail vein of conscious mice into chilled fluoride/heparin micro-centrifuge tubes (Sarstedt, Numbrecht, Germany) and centrifuged at $13,000 \boldsymbol{g}$ for 30 s (Beckman Instruments, Galway, Ireland). Glucose concentrations were measured using Ascencia Contour Blood Glucose Meter (Bayer Healthcare) and plasma/pancreatic insulin determined using modified dextran-coated charcoal RIA (Flatt \& Bailey 1981). HOMA-IR and HOMA- $\beta$ were determined from calculations as described previously (Gault et al. 2015). Lipids (total cholesterol - CH200; and triglycerides TR210) and ALT (AL1205) were measured using enzymatic kits from Randox Laboratories (Crumlin, UK). Plasma corticosterone (ab100712) and IL-6 (ab108821) were measured using enzymatic kits from Abcam and analysed with SOFTMAX PRO Software, version 5.2 on Flexstation 3 (Molecular Devices, Sunnyvale, CA, USA). Glucagon and total GLP-1 were measured by ELISA (EZGLU-30K and EZGLP1T-36K, respectively; Millipore). HbA1c was determined with a commercially available kit (HB-3058; Chirus Limited, Watford, UK). Percentage fat and lean mass were measured using DEXA densitometry (Piximus Densitometer, USA) as described previously (Millar et al. 2016).

\section{Assessment of learning and memory}

Open-field and novel recognition tests were performed as described previously (Lennox et al. 2014). Briefly, mice were placed in an arena and motor activity (speed and path length), anxiety (grooming events) and exploration (rearing events) recorded over 5-min period. Twentyfourhours later, mice were placed back into the same arena and a novel object recognition task was conducted comprising a 10-min acquisition phase (followed by a 3-h rest in the home cage) followed by test trial where mice could explore familiar and novel object for $10 \mathrm{~min}$. Time spent exploring familiar or novel object was expressed as recognition index (RI) calculated as time (t) spent exploring novel object divided by time spent exploring both objects $(A+B) \times 10$. RIb $=t B / t(A+B) \times 100$ normalises all data for statistical comparison (Lennox et al. 2014).

\section{Immunohistochemistry and image analysis}

Mice were perfused with PBS transcardially as described previously (Parthsarathy et al. 2013). Pancreatic tissue was excised for immunohistochemistry, measurement of insulin/glucagon content and gene expression. For determination of pancreatic insulin and glucagon content, pre-weighed pancreatic tissue was washed thoroughly in ice-cold PBS, homogenised in acid ethanol solution (ethanol/0.7 M HCl; 3:1 ratio) and extracted overnight at $4^{\circ} \mathrm{C}$. Insulin content was measured by insulin radioimmunoassay and glucagon content determined by ELISA (EZGLU-30K; Millipore). For histology, pancreatic tissues were fixed in $4 \%$ paraformaldehyde for $48 \mathrm{~h}$ at $4^{\circ} \mathrm{C}$, processed using automated tissue processor (Leica TP1020, Leica Microsystems) and embedded in paraffin wax. Immunohistochemistry was performed as described previously (Moffett et al. 2015). Following primary antibodies were used: mouse monoclonal anti-insulin antibody (ab6995, 1:1000; Abcam), guniea-pig antiglucagon antibody (PCA2/4, 1:400; raised in-house),

Published by Bioscientifica Ltd 
rabbit polyclonal anti-GLP-1 antibody (XJIC8, 1:200; raised in-house) and mouse polyclonal anti-IL-6 details (PM626, 1:200; Thermo Fisher Scientific). Secondary antibodies used as appropriate: Alexa Fluor 488 goat antiguinea pig IgG - 1:400, Alexa Fluor 594 goat anti-mouse IgG - 1:400. Slides were viewed under FITC filter $(488 \mathrm{~nm})$ or TRITC filter $(594 \mathrm{~nm})$ using fluorescent microscope (Olympus BX51) and DP70 camera adapter system. Brain processing and immunostaining were performed as described previously (Parthsarathy et al. 2013). Briefly, 40 micron thick coronal sections of brains at anatomical regions -2 to -3 bregma were stained for young immature neurons (anti-doublecortin, 1:200 dilution, sc-8066, Santa Cruz Biotechnology) and synaptic density (antisynaptophysin, 1:200 dilution, Abcam, ab-7837).

\section{Image analysis}

Alpha and beta cell area were analysed in a blinded manner using Cell^ ${ }^{\wedge}$ image analysis software (Olympus Soft Imaging Solutions, $\mathrm{GmbH}$ ) and expressed as $\mu \mathrm{m}^{2}$. Briefly, fluorescent images were captured using digital camera and closed polygon tool in Cell^ ${ }^{\wedge}$ used to analyse alpha cell and beta cell area. Pixel area was converted to $\mu \mathrm{m}^{2}$ and plotted in Prism. To quantify cell proliferation and neurogenesis, DCX-labelled immature neurons were counted in sub-granular zone of dentate gyrus. Minimum of seven coronal sections per animal were counted using $40 \times$ objective of bright field microscope (Olympus BX51) and plotted as average number of positive cells per section. Synaptophysin staining was analysed with Image (NIH) software using corrected O.D. method (McClean et al. 2011). Briefly, following adjustment for optimum resolution, calibration for optical density was performed using Kodak No. 3 step tablet (Tiffen, Kodak) and calibration curve was obtained as described in ImageJ software. Using $10 \times$ magnification objective, image for each area of interest was obtained per section (4-5 sections per mouse brain) with digital camera. Area of interest comprised hippocampus and cortex that included polymorphic layer, granular cell layer, molecular layer, stratum radiatum, stratum pyramidal, stratum oriens, interior and exterior cortical layers. Images were converted to 8-bit grey scale and pixel density was obtained from three small randomly selected squares per layer converted to O.D. using calibration curve. Average O.D. values for each layer were subtracted from average O.D. values of granular cell layer (GCL) and corrected O.D. was plotted.

\section{Gene expression}

mRNA was extracted (Tripure Isolation Reagent; Roche Diagnostics), quantified and purity determined using nanophotometer (Implen, Munich, Germany). cDNA was synthesised using Transcriptor First-Strand cDNA Synthesis Kit (Roche Diagnostics), and gene expression analysis for insulin and glucagon performed on whole pancreas by qPCR using Light Cycler 480 Probes Master (Roche Diagnostics) according to manufacturer's instructions (Gault et al. 2015). HPRT and beta-actin were used as internal control for normalisation. PCR conditions were $95^{\circ} \mathrm{C}$ for $10 \mathrm{~min}$, followed by cDNA amplification for 50 cycles with $95^{\circ} \mathrm{C}$ denaturation for $10 \mathrm{~s}, 60^{\circ} \mathrm{C}$ annealing for $30 \mathrm{~s}$ and $72^{\circ} \mathrm{C}$ elongation for $10 \mathrm{~s}$ followed by cooling period of $30 \mathrm{~s}$ at $40^{\circ} \mathrm{C}$. Relative quantification using $2^{-\Delta \Delta \mathrm{CT}}$ method was used to calculate the differences between groups (Livak \& Schmittgen 2001).

\section{Statistical analyses}

Results were analysed using Prism (GraphPad Software) and data were expressed as mean \pm S.E.M. For metabolic data, statistical analyses were performed using one-way ANOVA followed by Student-Newman-Keuls post hoc test.
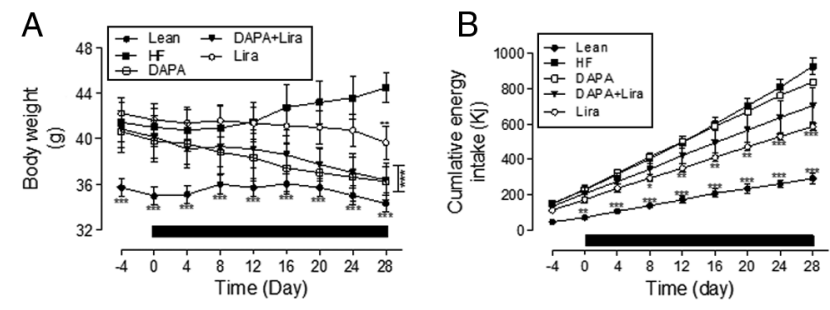

C
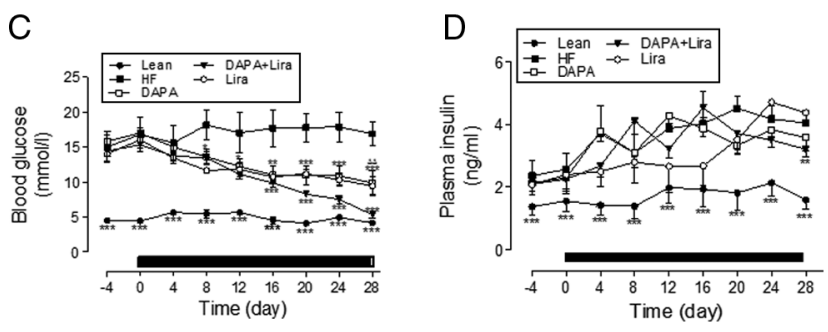

\section{Figure 1}

Effects of once-daily administration of DAPA-Lira on (A) body weight, (B) cumulative energy intake, (C) glucose and (D) insulin concentrations. $\mathrm{HF}$ mice received saline vehicle $(0.9 \% \mathrm{wt} / \mathrm{vol}$; p.o.), dapagliflozin ( $1 \mathrm{mg} / \mathrm{kg}$; p.o.), dapagliflozin ( $1 \mathrm{mg} / \mathrm{kg}$; p.o.) plus liraglutide ( $25 \mathrm{nmol} / \mathrm{kg}$; i.p.) or liraglutide alone ( $25 \mathrm{nmol} / \mathrm{kg}$; i.p.) over 28 days. Lean control mice received saline vehicle once-daily. Metabolic parameters were measured every 3-4 days. Values are means \pm S.E.M. for groups of 8-10 mice. ${ }^{*} P<0.05, * * P<0.01$ and $* * * P<0.001$ compared to HF controls. $\Delta \Delta P<0.01$ compared to DAPA-Lira.
() 2017 Society for Endocrinology Printed in Great Britain
Published by Bioscientifica Ltd 
A
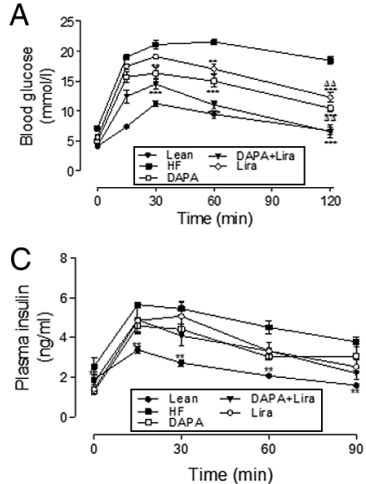

Figure 2

Effects of once-daily administration of DAPA-Lira on (A and B) glucose tolerance and ( $C$ and $D)$ insulin response to glucose. $\mathrm{HF}$ mice received saline vehicle ( $0.9 \% \mathrm{wt} / \mathrm{vol}$; p.o.), dapagliflozin ( $1 \mathrm{mg} / \mathrm{kg}$; p.o.), dapagliflozin ( $1 \mathrm{mg} / \mathrm{kg}$; p.o.) plus liraglutide $(25 \mathrm{nmol} / \mathrm{kg}$; i.p.) or liraglutide alone $(25 \mathrm{nmol} / \mathrm{kg}$; i.p.) over 28 days. Lean control mice received saline vehicle once-daily. Glucose and insulin concentrations were measured prior to and after oral administration of glucose $(18 \mathrm{mmol} / \mathrm{kg})$ in 12 -h fasted mice. Glucose and insulin AUC values post injection are also shown. Values are means \pm S.E.M. for groups of $8-10$ mice. $* P<0.05, * * P<0.01$ and $* * * P<0.001$ compared to HF controls. $\triangle \triangle P<0.01$ and $\triangle \Delta \triangle P<0.001$ compared to DAPA-Lira.

For novel object recognition and immunohistochemistry, statistical analyses were carried out using unpaired Student's $t$-test (non-parametric, with two-tailed $P$ values and 95\% confidence interval) and one-way ANOVA with Bonferroni post hoc test. Groups of data were considered to be significantly different if $P<0.05$.

\section{Results}

\section{Effects of DAPA-Lira on body weight, energy intake and glucose and insulin concentrations}

Compared to HF controls, DAPA-Lira treatment resulted in significant time-dependent decrease in body weight
$(P<0.001$; Fig. 1A). Importantly, body weights for DAPALira and dapagliflozin groups were reduced despite no reduction in energy intake (Fig. 1B). Liraglutide-treated mice displayed reduced cumulative energy intake $(P<0.05-P<0.001$; Fig. $1 \mathrm{~B})$ compared to HF controls. DAPA-Lira treatment resulted in time-dependent decrease (242\%; $P<0.001)$ in glucose concentrations compared to HF controls, dapagliflozin or liraglutide alone (157-172\%; $P<0.01$ ) on day 28 (Fig. 1C). All treatments exhibited progressive time-dependent increase in insulin but no significance was detected between HF groups, except DAPA-Lira-treated mice, which exhibited lower levels on day $28(P<0.01$; Fig. 1D).

\section{Effects of DAPA-Lira on glucose tolerance, insulin response to glucose, insulin sensitivity, HbA1c and plasma glucagon}

Mice treated with DAPA-Lira for 28 days exhibited significant reduction $(37-47 \%$ decrease; $P<0.01)$ in glucose concentrations (individual time-course for up to $120 \mathrm{~min}$ ) compared with dapagliflozin or liraglutide alone (Fig. 2A). This was further corroborated by significantly reduced glucose $\mathrm{AUC}_{120}$ values (37-52\% decrease; $P<0.001$; Fig. 2B). As shown in Fig. 2C, all treatment groups demonstrated increased insulinotropic response, with DAPA-Lira mice exhibiting significantly higher $\mathrm{AUC}_{90}$ values (1.1-1.4-fold increase; $P<0.01-$ $P<0.001)$ compared to dapagliflozin or liraglutide alone (Fig. 2D). Similarly, all treatment groups displayed marked improvement in insulin sensitivity compared to $\mathrm{HF}$ controls following administration of exogenous insulin $(P<0.05$; Fig. 3A and B). DAPA-Lira-treated mice also displayed marked reduction $(73 \%$ lower; $P<0.05)$ in HOMA-IR compared to dapagliflozin or liraglutide alone
A

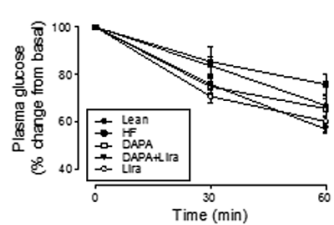

D

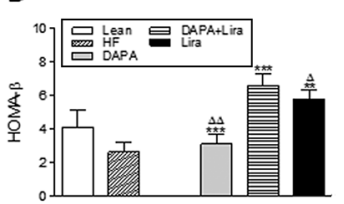

B

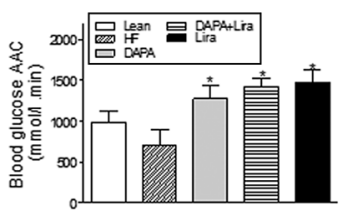

E

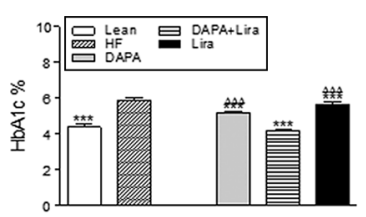

C

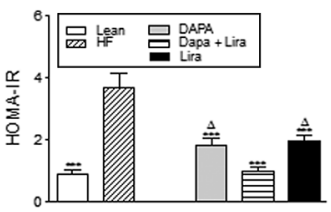

$\mathrm{F}$

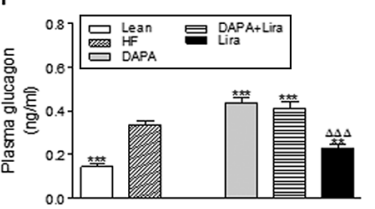

Figure 3

Effects of once-daily administration of DAPA-Lira on ( $A$ and $B$ ) insulin sensitivity, (C) HOMA-IR, (D) HOMA- $\beta$, (E) HbA1c and (F) plasma glucagon. $\mathrm{HF}$ mice received saline vehicle ( $0.9 \% \mathrm{wt} / \mathrm{vol}$; p.o.), dapagliflozin (1 mg/kg; p.o.), dapagliflozin (1 mg/kg; p.o.) plus liraglutide $(25 \mathrm{nmol} / \mathrm{kg}$; i.p.) or liraglutide alone $(25 \mathrm{nmol} / \mathrm{kg}$; i.p.) over 28 days. Lean control mice received saline vehicle once-daily. Parameters were measured at the end of the study period. For insulin sensitivity, glucose concentrations were measured prior to and after injection of insulin (25U/kg; i.p.) in non-fasted mice. Glucose AAC values post injection are also shown. Values are means \pm S.E.M. for groups of 8-10 mice. ${ }^{* *} P<0.01$ and $* * * P<0.001$ compared to $\mathrm{HF}$ controls. $\triangle P<0.05, \triangle \Delta P<0.01$ and $\triangle \Delta \triangle P<0.001$ compared to DAPA-Lira. 
A

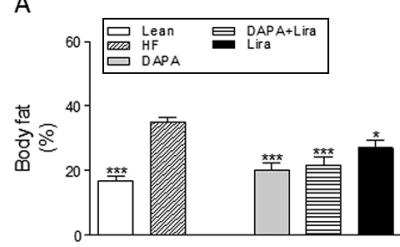

B
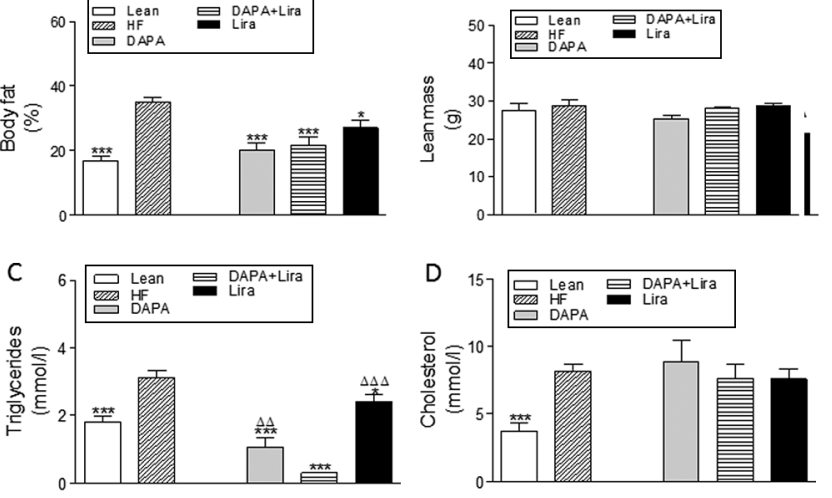

Figure 4

Effects of once-daily administration of DAPA-Lira on (A) fat mass, (B) lean mass, (C) triglycerides and (D) total cholesterol. HF mice received saline vehicle ( $0.9 \% \mathrm{wt} / \mathrm{vol}$; p.o.), dapagliflozin ( $1 \mathrm{mg} / \mathrm{kg} ;$ p.o.), dapagliflozin ( $1 \mathrm{mg} / \mathrm{kg}$; p.o.) plus liraglutide $(25 \mathrm{nmol} / \mathrm{kg}$; i.p.) or liraglutide alone ( $25 \mathrm{nmol} / \mathrm{kg}$; i.p.) over 28 days. Lean control mice received saline vehicle once-daily. Parameters were measured at the end of the study period. Values are means \pm S.E.M. for groups of $8-10$ mice. ${ }^{*} P<0.05$ and $* * * P<0.001$ compared to HF controls. $\Delta \Delta P<0.01$ and $\triangle \Delta \Delta P<0.001$ compared to DAPA-Lira.

(Fig. 3C). Furthermore, mice treated with DAPA-Lira had a significantly improved HOMA- $\beta$ index compared to dapagliflozin (53\% increase; $P<0.01)$ or liraglutide $(13 \%$ increase; $P<0.05$ ) alone (Fig. 3D). All treatment groups had significantly $(P<0.001)$ reduced $\mathrm{HbA1c}$ values compared to HF controls with DAPA-Lira-treated mice exhibiting improved HbA1c (19-26\% reduction; $P<0.001)$ compared to dapagliflozin or liraglutide alone (Fig. 3E). Dapagliflozin and DAPA-Lira groups had significantly increased plasma

glucagon concentrations $(24-33 \% ; P<0.001)$ compared to HF controls, whereas liraglutide group exerted a $33 \%$ reduction in plasma glucagon $(P<0.001)$ compared to DAPA-Lira-treated mice (Fig. 3F).

\section{Effects of DAPA-Lira on body composition and lipids}

DEXA analysis revealed that all treatment groups exhibited significant reduction $(37-42 \%$ decrease; $P<0.05-$ $P<0.001)$ in percentage fat mass compared to HF controls (Fig. 4A). No significant differences were noted between DAPA-Lira and liraglutide or dapagliflozin. Similarly, no significant differences were observed in lean mass for any groups tested (Fig. 4B). Compared with HF controls, all treatments significantly decreased triglycerides $(P<0.5-$ $P<0.001$; Fig. 4C). DAPA-Lira reduced triglycerides (71-87\% decrease; $P<0.01-P<0.001$; Fig. 4 C) to a greater extent than either liraglutide or dapagliflozin alone. No significant differences between HF groups in terms of total cholesterol was observed (Fig. 4D).

\section{Effects of DAPA-Lira on terminal organ weight, hormones and biomarkers}

Administration of DAPA-Lira and dapagliflozin resulted in a significant reduction in inguinal adipose weight $(P<0.05$; Fig. 5A). Liver and pancreatic weights were not significantly different in any of the HF groups (Fig. 5B and C). Total plasma GLP-1 concentrations were significantly
A
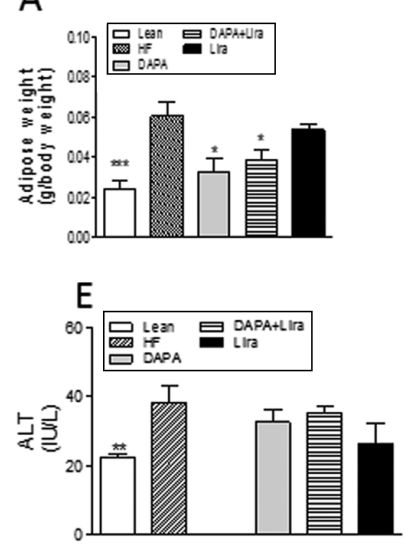

B

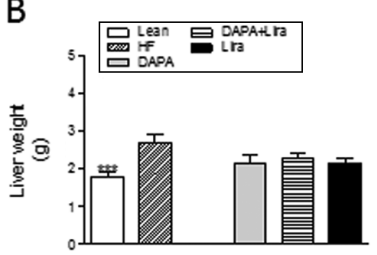

F

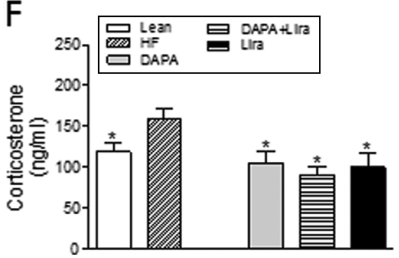

C
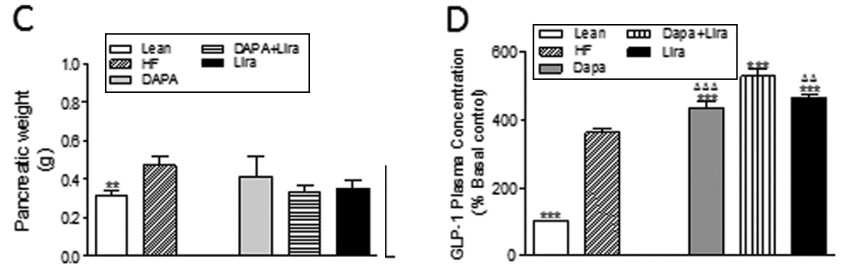

G

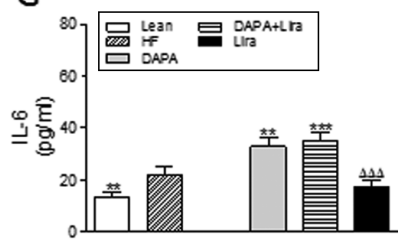

\section{Figure 5}

Effects of once-daily administration of DAPA-Lira on (A) adipose weight, (B) liver weight, (C) pancreatic weight, (D) total GLP-1, (E) ALT, (F) corticosterone and (G) IL-6 concentrations. HF mice received saline vehicle (0.9\% wt/vol; p.o.), dapagliflozin (1 mg/kg; p.o.), dapagliflozin (1 mg/kg; p.o.) plus liraglutide $(25 \mathrm{nmol} / \mathrm{kg}$; i.p.) or liraglutide alone $(25 \mathrm{nmol} / \mathrm{kg}$; i.p.) over 28 days. Lean control mice received saline vehicle once-daily. Parameters were measured at the end of the study period. Values are means \pm S.E.M. for groups of 8-10 mice. ${ }^{*} P<0.05, * * P<0.01$ and $* * * P<0.001$ compared to HF controls. $\Delta \Delta P<0.01$ and $\Delta \Delta P<0.001$ compared to DAPA-Lira. 
A

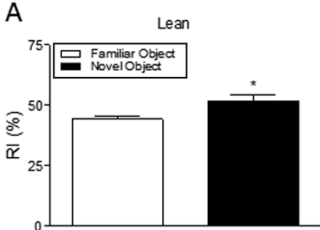

D

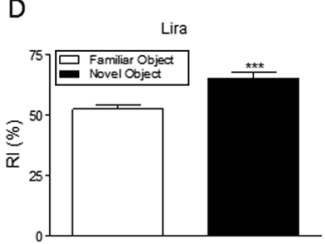

B

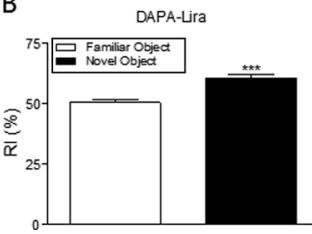

E

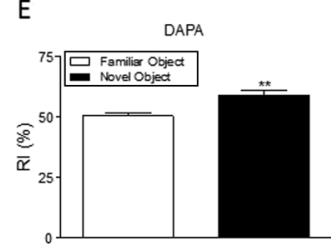

$\mathrm{C}$

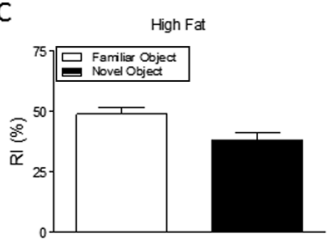

$\mathrm{F}$

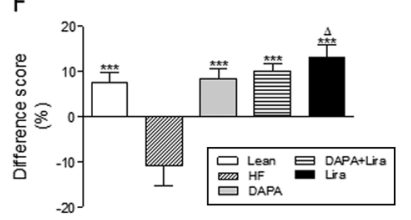

\section{Figure 6}

Effects of once-daily administration of DAPA-Lira on recognition index for (A) HF, (B) DAPA, (C) DAPA-Lira, (D) Lira, (E) lean mice and (F) difference score. $\mathrm{HF}$ mice received saline vehicle ( $0.9 \%$ wt $/$ vol; p.o.), dapagliflozin ( $1 \mathrm{mg} / \mathrm{kg} ;$ p.o.), dapagliflozin (1 mg/kg; p.o.) plus liraglutide $(25 \mathrm{nmol} / \mathrm{kg}$; i.p.) or liraglutide alone $(25 \mathrm{nmol} / \mathrm{kg}$; i.p.) over 28 days. Lean control mice received saline vehicle once-daily. Parameters were measured at the end of the study period. Values are means \pm S.E.M. for groups of 8-10 mice. $* P<0.05, * * P<0.01$ and $* * * P<0.001$ compared to HF controls. $\triangle P<0.05$ compared to DAPA-Lira. increased in all treatment groups $(P<0.001)$ compared to HF controls with DAPA-Lira group displaying increased levels of total GLP-1 $(12-18 \%$ increase; $P<0.01-$ $P<0.001)$ compared to liraglutide or dapagliflozin alone (Fig. 5D). No significant differences were noted in ALT levels in HF mice (Fig. 5E). Both dapagliflozin and DAPALira treatment groups displayed significantly elevated (1.0-fold; $P<0.01-P<0.001)$ plasma IL-6 levels compared to HF controls (Fig. 5F). Liraglutide-only treated mice displayed reduced (48\% decrease; $P<0.001)$ IL-6 levels compared to DAPA-Lira treatment (Fig. 5F). All treatment groups resulted in significant reduction (33-43\% decrease; $P<0.05)$ in corticosterone concentrations compared to HF controls (Fig. 5G).

\section{Effects of DAPA-Lira in novel object recognition task}

During test trial, no significant difference was noted in the RI for the HF group indicating that they could not discriminate between novel and familiar object thereby exhibiting impaired cognition (Fig. 6A). All treatment groups and lean control group displayed significantly increased RI $\quad(1.1-1.3$-fold; $P<0.01-P<0.001)$ when exposed to novel object compared to HF controls, thus highlighting preference to explore novel vs familiar object (Fig. 6B, C, D, E and F). Open-field assessment revealed no effect of any treatments on motor activity (speed and path length), anxiety (grooming events) and exploration (rearing events) (data not shown).

\section{Effects of DAPA-Lira on islet morphology, pancreatic hormone content and mRNA gene expression}

As shown in Fig. 7A, beta cell area was significantly increased $(P<0.05)$ in liraglutide-treated mice. Mice treated with dapagliflozin alone exhibited marked increase $(P<0.01)$ in alpha cell area compared to HF controls (Fig. 7D). In contrast, DAPA-Lira or liraglutide alone did not affect alpha cell area (Fig. 7D). Islets of HF mice exhibited substantial staining for IL-6 in beta cells and GLP-1 in alpha cells with no appreciable differences between various treatment groups (images not shown). Both DAPA-Lira and liraglutide markedly increased (1.4-1.6 fold; $P<0.05)$ pancreatic insulin content compared to HF controls (Fig. 7B). Liraglutide treatment also significantly decreased $(23 \%$ reduction; $P<0.001)$ glucagon content
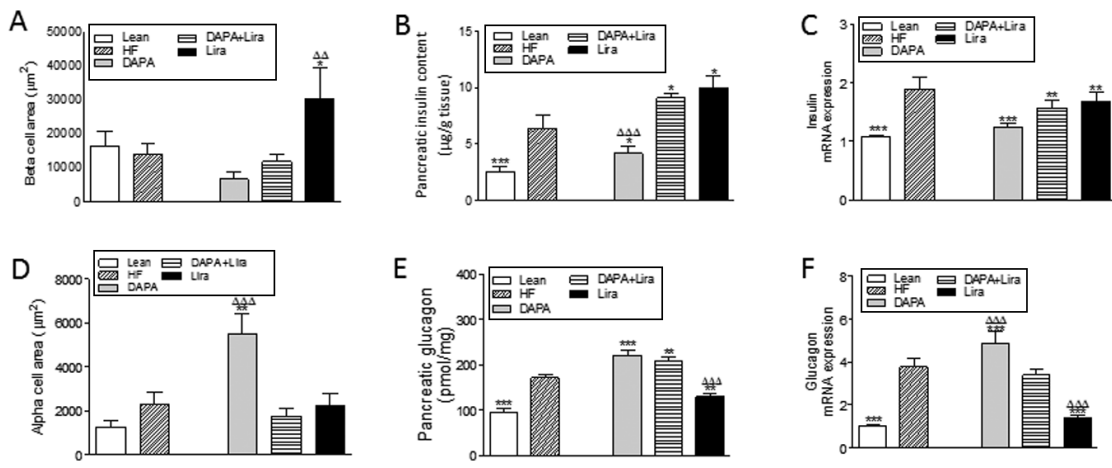

Figure 7

Effects of once-daily administration of DAPA-Lira on (A) beta cell area, (B) insulin content,

(C) insulin mRNA expression, (D) alpha cell area, (E) glucagon content and (F) glucagon mRNA expression. HF mice received saline vehicle (0.9\% wt/vol; p.o.), dapagliflozin ( $1 \mathrm{mg} / \mathrm{kg}$; p.o.), dapagliflozin (1 mg/kg; p.o.) plus liraglutide $(25 \mathrm{nmol} / \mathrm{kg}$; i.p.) or liraglutide alone $(25 \mathrm{nmol} / \mathrm{kg}$; i.p.) over 28 days. Lean control mice received saline vehicle once-daily. Parameters were measured at the end of the study period. Values are means \pm S.E.M. for groups of 8-10 mice. ${ }^{*} P<0.05, * * P<0.01$ and $* * * P<0.001$ compared to HF controls. $\triangle \Delta P<0.01$ and $\triangle \Delta \triangle P<0.001$ compared to DAPA-Lira. 
while both DAPA-Lira and dapagliflozin led to significant increases compared to HF controls (21-28\% increase; $P<0.01-P<0.001$; Fig. 7E). A similar pattern to changes in pancreatic insulin and glucagon content were observed in pancreatic mRNA expression of insulin and glucagon (Fig. 7C and F).

\section{Effects of DAPA-Lira on neurogenesis and synaptic density}

Representative micrographs of doublecortin and synaptophysin staining are shown in Fig. 8A, B, C, D and E. Mice treated with DAPA-Lira, dapagliflozin or liraglutide displayed increased number of immature neurons in the dentate gyrus $(44-69 \%$ increase; $P<0.01-$ $P<0.001$; Fig. 8F) compared to HF controls as indicated by increased number of DCX-positive cells. Significantly higher levels of synaptophysin expression were demonstrated in all treatment groups in stratum oriens layer (88-113\% increase; $P<0.01$; Fig. 8J) compared to HF controls. DAPA-Lira treatment also improved synaptophysin expression in stratum pyramidale layer (50\% increase; $P<0.05$; Fig. 8I), though no differences in polymorph layer (Fig. 8G) and stratum radiatum (Fig. $8 \mathrm{H}$ ) were observed.

\section{Discussion}

Given the increase and diversity of new antidiabetic drugs in the clinic, there is now a great opportunity to offer a more patient-centred tailored or personalised approach to therapeutic intervention. In this study, we examined the efficacy of combination therapy using the SGLT2 inhibitor dapagliflozin and the long-acting GLP-1 agonist liraglutide. In addition to assessing metabolic outcomes, we also examined potential neuroprotective benefits of combination therapy on learning and memory, especially since recent evidence has shown that GLP-1 agonists may reduce cognitive decline in diabetes-obesity (Gault et al. 2010, Porter et al. 2013).

We chose to use a rodent model of diabetes combining low-dose STZ and high-fat feeding to promote obesity, insulin resistance and hyperglycaemia (Srinivasan et al. 2005, Islam \& Wilson 2012). This rodent model has been used previously and serves as a suitable means to evaluate potential drug intervention (Bhat et al. 2013, Millar et al. 2016). A small dose of STZ was combined with high-fat feeding to inflict sub-lethal damage to beta cells, which when combined with high-fat feeding gave a more rapid and pronounced diabetes phenotype with elevation in blood glucose concentrations. SGLT2 inhibitors act by reabsorbing glucose so it is useful to study therapeutic
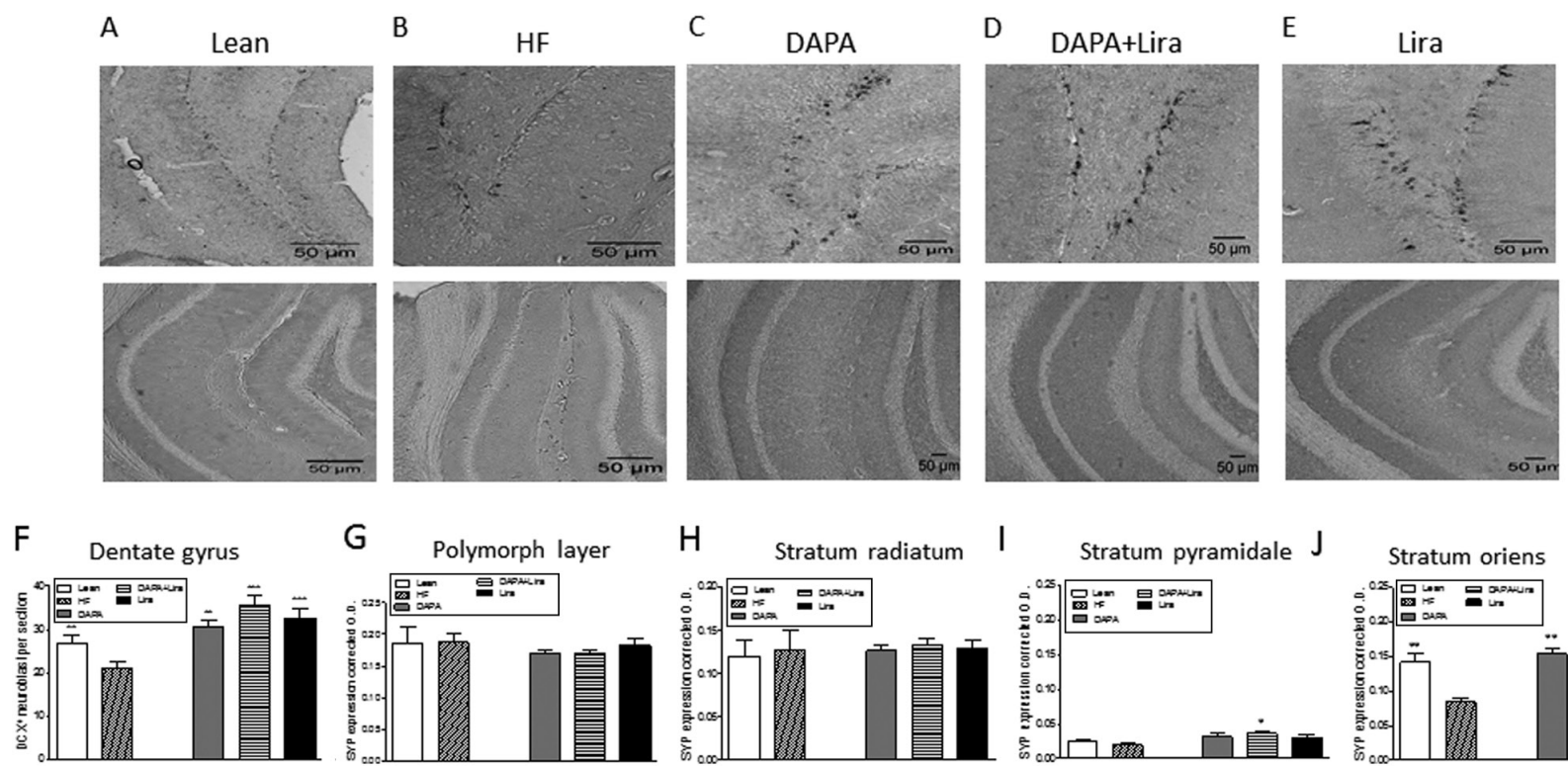

G Polymorph layer
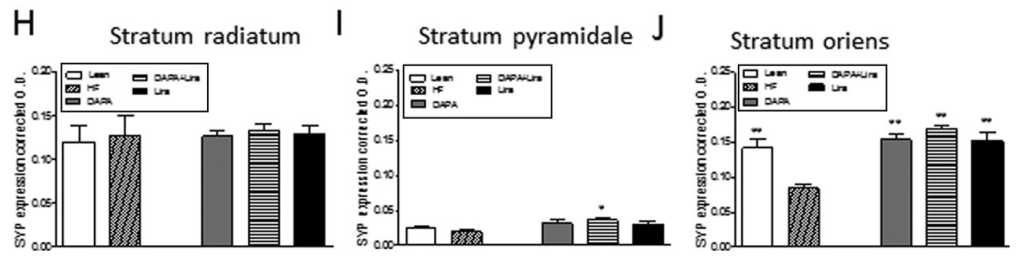

Figure 8

Effects of once-daily administration of DAPA-Lira on (A, B, C, D and E) brain immunohistochemistry, (F) doublecortin neuroblast, and quantification levels of synaptophysin expression in (G) polymorph layer, $(\mathrm{H})$ stratum radiatum, $(\mathrm{I})$ stratum pyramidale and $(\mathrm{J})$ stratum oriens layer. $\mathrm{HF}$ mice received saline vehicle (0.9\% wt/vol; p.o.), dapagliflozin ( $1 \mathrm{mg} / \mathrm{kg} ;$ p.o.), dapagliflozin (1 mg/kg; p.o.) plus liraglutide ( $25 \mathrm{nmol} / \mathrm{kg}$; i.p.) or liraglutide alone ( $25 \mathrm{nmol} / \mathrm{kg}$; i.p.) over 28 days. Lean control mice received saline vehicle once-daily. Parameters were measured at the end of the study period. Values are means \pm S.E.M. for groups of 6 mice. ${ }^{*} P<0.05, * * P<0.01$ and $* * * P<0.001$ compared to HF controls. 
effects when glucose levels are significantly raised. In contrast to liraglutide, DAPA-Lira combination therapy over 28 days did not affect energy intake. This is an important observation as several studies suggested that energy intake is increased following SGLT2 inhibitor therapy (Devenny et al. 2012, Nagata et al. 2013). As expected, all treatments resulted in reduced body weight, which in the case of dapagliflozin most presumably reflects energy loss via urinary glucose excretion (Scheen \& Paquot 2014). SGLT2 inhibitors induce a significant and durable weight loss in patients with T2DM (Bailey et al. 2015).

Consistent with previous studies, monotherapy with dapagliflozin or liraglutide decreased glucose concentrations both in terms of non-fasting concentrations and following an oral glucose challenge. Moreover, DAPALira combination therapy resulted in a more pronounced glucose-lowering effect that is most likely achieved through increased urinary glucose excretion (Bailey et al. 2016) and enhanced beta cell function. Interestingly, dapagliflozin monotherapy was also associated with enhanced glucose-induced insulin secretion and HOMA- $\beta$, which could be due to improved metabolic control and reversal of beta cell glucotoxicity, a potential direct effect on beta cells and possible involvement of effects on other hormones such as GLP-1 as observed with less selective SGLT2 inhibitors (Zambrowicz et al. 2013). Indeed, plasma GLP-1 concentrations were significantly increased in all treatment groups at the end of the study but most notably in the group receiving DAPA-Lira combination therapy. This may well point to enhanced alpha cell GLP-1 production, which has been observed previously in pregnancy and situations of beta cell stress (Moffett et al. 2014, Vasu et al. 2014). Interestingly, IL-6 that has been implicated in islet processing of proglucagon to GLP-1 via increased expression of PC1/3 (Ellingsgaard et al. 2011) was markedly increased in beta cells of all HF groups.

All treatment groups exhibited improved insulin sensitivity and improved HOMA-IR. These changes in insulin sensitivity may be ascribed to weight reduction and alleviation of glucose toxicity (Macdonald et al. 2010). Of particular note is the observation that DAPA-Lira combination therapy markedly reduced $\mathrm{HbA1c}$, which was significantly lower than either dapagliflozin or liraglutide alone. Importantly, no episodes of hypoglycaemia were observed in treatment groups following fasting for OGTT or during the insulin tolerance test; however, measurement of circulating ketones would have been informative. Taken together, DAPA-Lira combination therapy was associated with improved glucose-lowering and greater reduction in body weight (compared to liraglutide alone), without observable effects on energy intake, suggesting that combination of dapagliflozin and liraglutide is a very powerful approach to management of glycaemia.

Consistent with previous studies, high-fat-fed mice exhibited dyslipidaemia and obesity (Podrini et al. 2013). DEXA scanning revealed that fat mass was significantly reduced in all treatment groups with a tendency to be lower in groups treated with dapagliflozin, and this was further corroborated by significantly decreased adipose tissue mass. In T2DM patients, body weight loss induced by dapagliflozin is mainly due to reduction in visceral and subcutaneous fat mass (Bolinder et al. 2012). Importantly, decreases in fat mass were not associated with changes in lean mass. High-fat mice displayed elevated triglyceride concentrations that were significantly improved in all treatment groups but especially in DAPA-Lira combination group. This could be due to function of improved glycaemia and greater weight reduction in this group. No significant changes in plasma total cholesterol were noted in any of the treatment groups. Although not measured in this study, relatively small clinically insignificant increases in both LDL and HDL cholesterol have been observed in patients on dapagliflozin therapy (Matthaei et al. 2015). As expected, HF mice exhibited increased liver weight and ALT concentrations characteristic of non-alcoholic fatty liver disease (Ganz et al. 2014). Whilst all treatments tended to reverse negative effects towards that of healthy controls, more detailed analyses investigating effects on hepatic triglyceride content, plasma and liver oxidative stress would be useful.

Mice treated with dapagliflozin, either alone or in combination with liraglutide, displayed elevated levels of IL-6. IL-6 has been shown to stimulate insulin from beta cells, glucagon from alpha cells and GLP-1 secretion from both intestinal L and pancreatic alpha cells (Ehses et al. 2007, Ellingsgaard et al. 2008, 2011). Increase in GLP-1 production is thought to occur via differentiation of the alpha cell through proglucagon transcription and enhanced PC1/3 expression (Ellingsgaard et al. 2008, 2011). Furthermore, SGLT2 inhibition promotes glucagon secretion from alpha cells in healthy mice (Bonner et al. 2015) and increases GLP-1 concentrations in patients (Ferrannini et al. 2014). More recent studies have suggested that dapagliflozin stimulates GLP-1 and IL6 secretion from pancreatic islets (Timper et al. 2016). In the present study, dapagliflozin increased plasma GLP-1, glucagon and IL-6, perhaps pointing to an important role for IL6 in beneficial action of dapagliflozin. Indeed, we have recently demonstrated increased expression

Published by Bioscientifica Ltd. 
of PC1/3 in $\alpha$ TC1.9 cells treated with dapagliflozin (unpublished observations). Measures of additional circulating cytokines (e.g. TNF $\alpha$ and IL-1 $\beta$ ) would provide insight as to whether this reflects a specific effect on IL-6 or a more generalised heightened inflammatory state. The increase in plasma IL-6 following dapagliflozin therapy is particularly interesting and further studies exploring its role are clearly warranted. Importantly, mice treated with liraglutide alone displayed decreased plasma glucagon with no change in IL-6 concentrations.

Pancreatic immunochemical staining revealed that mice treated with dapagliflozin exhibited a significant increase in alpha cell area. This was accompanied by reduction in pancreatic insulin content and increases in both proglucagon gene expression and pancreatic glucagon content. These observations are broadly in line with metabolic insulin and glucagon data and further confirm an important effect of dapagliflozin on the alpha cell (Bonner et al. 2015). As expected, liraglutide treatment was associated with enhanced beta cell area and increased insulin content, and this was accompanied by significant decrease in gene expression and pancreatic glucagon content (Schwasinger-Schmidt et al. 2013). Interestingly, alpha cell area was not affected in mice receiving DAPA-Lira combination therapy with both insulin gene expression and hormone content increased, suggesting that the liraglutide component countered some of the alpha cell promoting properties of dapagliflozin, which would be beneficial in a longer-term treatment regimen. We did not see tight correlation between the various parameters (percentage islet cells, hormone content and basal hormone levels) because many different factors influence these parameters. For example, if cell synthesises hormone, it is not just leaked out into the blood but is stored in vesicles that are regulated on minute-tominute basis by prevailing blood glucose plus myriad of other factors.

We and others have previously shown that high-fat feeding in rodents causes detrimental effects in brain regions associated with learning and memory (Greenwood \& Winocur 2005, Stranahan et al. 2008a, Gault et al. 2010). Furthermore, growing evidence indicates that diabetes and obesity increase the risk of developing neurodegenerative disorders, such as AD (Rani et al. 2016). More recently, GLP-1 agonists (and DPP4 inhibitors) have been shown to reduce cognitive decline associated with diabetes-obesity (Groeneveld et al. 2016). The present study evaluated learning and memory using well-established novel object recognition task, which exploits the ability of a rodent to explore a novel object over a familiar object (Abbas et al. 2009). As expected, HF mice could not discriminate between familiar and novel object when compared to healthy controls (Gault et al. 2015). However, all HF treated mice displayed significantly improved recognition memory, which was not attributable to effects on anxiety or motor activity, as indicated in open field assessment. Future studies using additional behavioural tests such as Morris Water Maze would also be useful.

Corticosterone concentrations were markedly raised following high-fat feeding but treatment with dapagliflozin or liraglutide (both alone and in combination) reversed this effect. Raised glucocorticoid concentrations not only induce insulin resistance but also contribute to deficits in hippocampal function (Stranahan et al. 2008b). Indeed, reducing corticosterone concentrations can prevent diabetes-induced impairment of hippocampus-dependent learning (Stranahan et al. 2008c). Immunohistochemical staining revealed that HF-treated mice displayed significantly enhanced doublecortin and synaptophysin expression, indicating possible role of drug treatment to promote recovery of neurogenesis and synaptic density. It is possible that combination therapy over a longer time period may have resulted in superior neurogenesis and cognitive function compared to monotherapy. To our knowledge, this is the first study to report beneficial effects of dapagliflozin on cognitive function, neurogenesis and synaptic density. Whilst positive neuroprotective and growth factor-like effects of dapagliflozin on learning and memory are unlikely to occur as direct effect of SGLT2 inhibition in the brain itself, SGLT2 inhibitors are lipid-soluble and should cross the blood-brain barrier (Bakris et al. 2009). However, similar to DPP4 inhibitors, it is plausible that neuroprotective effects observed for dapagliflozin could be attributed to increased GLP-1 concentrations, which can then cross the bloodbrain barrier and/or actions of dapagliflozin to lower corticosterone concentrations. Whilst we cannot rule out that part of the neuroprotective effects may be dependent on improved peripheral glycaemia, further detailed studies to delineate mechanism for this improvement in cognitive function with dapagliflozin would be useful.

In summary, compared with either agent alone, DAPA-Lira combination therapy was associated with superior glucose lowering and significant reduction in body weight, indicating powerful and complementary approach to effectively manage hyperglycaemia. Part of this benefit appears to derive from the ability of liraglutide to decrease islet alpha cells. Other prominent http://joe.endocrinology-journals.org DOI: $10.1530 / \mathrm{JOE}-17-0263$ (c) 2017 Society for Endocrinology Printed in Great Britain
Published by Bioscientifica Ltd 
effects included normalisation of hypertriglyceridaemia and enhancements of both insulin secretion and action. Furthermore, DAPA-Lira combination therapy and indeed dapagliflozin monotherapy were effective in reversing memory impairment in diabetic mice. Moreover, changes in glucagon and GLP-1 following dapagliflozin treatment were associated with changes in IL-6, suggesting possible role of IL-6 in mediating some of the actions of SGLT2 inhibition. This study supports recent papers showing the clinical effectiveness of combination therapy with SGLT2 inhibition and stable GLP-1 mimetics in T2DM patients (DeFronzo 2017). Taken together, our results highlight an important personalised approach in utilising liraglutide in combination with dapagliflozin for further clinical evaluation in the treatment of diabetes and associated neurodegenerative disorders.

\section{Declaration of interest}

The authors declare that there is no conflict of interest that could be perceived as prejudicing the impartiality of the research reported.

\section{Funding}

These studies were supported by Department of Education and Learning PhD studentship to P J B M, Ulster University Strategic Research Funding, SAAD Trading and Contracting Company and European Regional Development Fund (ERDF) award to A J B under the EU Sustainable Competitiveness Programme for Northern Ireland 2007-2013.

\section{Author contribution statement}

P J B M contributed to study design, conduct/data collection, data analysis and writing of the manuscript. V P, R C M, V Parth and N M P contributed to conduct/data collection and data analysis. A J B and $M O^{\prime} K$ reviewed the manuscript. V A G and P R F contributed to study design, analysis and writing of the manuscript. All authors approved the final version of the manuscript.

\section{References}

Abbas T, Faivre E \& Hølscher C 2009 Impairment of synaptic plasticity and memory formation in GLP-1 receptor KO mice: interaction between type 2 diabetes and Alzheimer's disease. Behavioural Brain Research 205 265-271. (doi:10.1016/j.bbr.2009.06.035)

Agersø H, Jensen LB, Elbrønd B, Rolan P \& Zdravkovic M 2002 The pharmacokinetics, pharmacodynamics, safety and tolerability of NN2211, a new long-acting GLP-1 derivative, in healthy men. Diabetologia 45 195-202. (doi:10.1007/s00125-001-0719-z)

Ashraghi MR, Pagano G, Polychronis S, Niccolini F \& Politis M 2016 Parkinson's disease, diabetes and cognitive impairment. Recent Patents on Endocrine, Metabolic and Immune Drug Discovery 10 11-21. (doi:10.2174/1872214810999160628105549)

Bailey CJ, Morales Villegas EC, Woo V, Tang W, Ptaszynska A \& List JF 2015 Efficacy and safety of dapagliflozin monotherapy in people with type 2 diabetes: a randomized double-blind placebo-controlled 102week trial. Diabetic Medicine 32 531-541. (doi:10.1111/dme.12624)
Bailey CJ, Tahrani AA \& Barnett AH 2016 Future glucose-lowering drugs for type 2 diabetes. Lancet Diabetes and Endocrinology 4 350-359. (doi:10.1016/S2213-8587(15)00462-3)

Bakris GL, Fonseca VA, Skarma K \& Wright EM 2009 Renal sodiumglucose transport: role in diabetes mellitus and potential clinical implications. Kidney International 75 1272-1277. (doi:10.1038/ ki.2009.87)

Bhat VK, Kerr BD, Flatt PR \& Gault VA 2013 A novel GIP-oxyntomodulin hybrid peptide acting through GIP, glucagon and GLP-1 receptors exhibits weight reducing and anti-diabetic properties. Biochemical Pharmacology 85 1655-1662. (doi:10.1016/j.bcp.2013.03.009)

Bolinder J, Ljunggren Ö, Kulberg J, Johansson L, Wilding J, Langkilde AM, Sugg J \& Parikh S 2012 Effects of dapagliflozin on body weight, total fat mass, and regional adipose tissue distribution in patients with type 2 diabetes mellitus with inadequate glycemic control on metformin. Journal of Clinical Endocrinology and Metabolism 97 1020-1031. (doi:10.1210/jc.2011-2260)

Bonner C, Kerr-Conte J, Gmyr V, Queniat G, Moerman E, Thévenet J, Beaucamps C, Delalleau N, Popescu I, Malaisse WJ, et al. 2015 Inhibition of the glucose transporter SGLT2 with dapagliflozin in pancreatic alpha cells triggers glucagon secretion. Nature Medicine 21 512-517. (doi:10.1038/nm.3828)

da Rocha Fernandes J, Ogurtsova K, Linnenkamp U, Guariquata L, Seuring T, Zhang P, Cavan D \& Makaroff LE 2016 IDF diabetes atlas estimates of 2014 global health expenditures on diabetes. Diabetes Research and Clinical Practice 117 48-54. (doi:10.1016/j. diabres.2016.04.016)

DeFronzo RA 2017 Combination therapy with GLP-1 receptor agonist and SGLT2 inhibitor. Diabetes Obesity and Metabolism [in press]. (doi:10.1111/dom.12982)

Devenny JJ, Godonis HE, Harvey SJ, Rooney S, Cullen MJ \& Pelleymounter MA 2012 Weight loss induced by chronic dapagliflozin treatment is attenuated by compensatory hyperphagia in diet-induced obese (DIO) rats. Obesity 20 1645-1652. (doi:10.1038/oby.2012.59)

Ehses JA, Perren A, Eppler E, Ribaux P, Pospisilik JA, Maor-Cahn R, Gueripel X, Ellingsgaard H, Schneider MK, Biollaz G, et al. 2007 Increased number of islet-associated macrophages in type 2 diabetes. Diabetes 56 2356-2370. (doi:10.2337/db06-1650)

Ellingsgaard H, Ehses JA, Hammar EB, Van Lommel L, Quintens R, Martens G, Kerr-Conte J, Pattou F, Berney T, Pipeleers D, et al. 2008 Interleukin-6 regulates pancreatic alpha-cells expansion. PNAS 105 13163-13168. (doi:10.1073/pnas.0801059105)

Ellingsgaard H, Hauselmann I, Schuler B, Habib AM, Baggio LL, Meier DT, Eppler, E, Bouzakri K, Wueest S, Muller YD, et al. 2011 Interleukin-6 enhances insulin secretion by increasing glucagon-like peptide-1 secretion from L cells and alpha cells. Nature Medicine 17 1481-1489. (doi:10.1038/nm.2513)

Ferrannini E, Muscelli E, Frascerra S, Baldi S, Mari A, Heise T, Broedl UC \& Woerle HJ 2014 Metabolic response to sodium-glucose cotransporter 2 inhibition in type 2 diabetic patients. Journal of Clinical Investigation 124 499-508. (doi:10.1172/JCI72227)

Flatt PR \& Bailey CJ 1981 Abnormal plasma glucose and insulin responses in heterozygous lean (ob/+) mice. Diabetologia 20 573-577.

Ganz M, Csak T \& Szabo G 2014 High fat feeding results in gender specific steatohepatitis and inflammasome activation. World Journal of Gastroenterology 20 8528-8534. (doi:10.3748/wjg.v20.i26.8525)

Gault VA, Porter WD, Flatt PR \& Hölscher C 2010 Actions of exendin-4 therapy on cognitive function and hippocampal synaptic plasticity in mice fed a high-fat diet. International Journal of Obesity 34 1341-1344. (doi:10.1038/ijo.2010.59)

Gault VA, Lennox R \& Flatt PR 2015 Sitagliptin, a dipeptidyl peptidase-4 inhibitor, improves recognition memory, oxidative stress and hippocampal neurogenesis and upregulates key genes involved in cognitive decline. Diabetes Obesity and Metabolism 17 403-413. (doi:10.1111/dom.12432) http://joe.endocrinology-journals.org

DOI: $10.1530 / J O E-17-0263$
๑ 2017 Society for Endocrinology Printed in Great Britain 
Gerich JE, Meyer C, Woerle HJ \& Stumvoll M 2001 Renal gluconeogenesis: its importance in human glucose homeostasis. Diabetes Care 24 382-391. (doi:10.2337/diacare.24.2.382)

Greenwood CE \& Winocur G 2005 High-fat diets, insulin resistance and declining cognitive function. Neurobiology of Aging 26 42-45. (doi:10.1016/j.neurobiolaging.2005.08.017)

Groeneveld ON, Kapelle LJ \& Biessels GJ 2016 Potentials of incretin-based therapies in dementia and stroke in type 2 diabetes mellitus. Journal of Diabetes Investigation 7 5-16. (doi:10.1111/jdi.12420)

Han S, Hagan DL, Taylor JR, Xin L, Meng W, Biller SA, Wetterau JR, Washburn WN \& Whaley JM 2008 Dapagliflozin, a selective SGLT2 inhibitor, improves glucose homeostasis in normal and diabetic rats. Diabetes 57 1723-1729. (doi:10.2337/db07-1472)

Hediger MA \& Rhoads DB 1994 Molecular physiology of sodium-glucose cotransporters. Physiological Reviews 74 993-1026.

Islam MS \& Wilson RD 2012 Experimentally induced rodent models of type 2 diabetes. Methods in Molecular Biology 933 161-174. (doi:10.1007/978-1-62703-068-7_10)

Knudsen LB, Nielsen PF, Huusfeldt PO, Johansen NL, Madsen K, Pedersen FZ, Thøgersen H, Wilken M \& Agersø H 2000 Potent derivatives of glucagon-like peptide- 1 with pharmacokinetic properties suitable for once daily administration. Journal of Medicinal Chemistry 43 1664-1669. (doi:10.1021/jm9909645)

Lennox R, Flatt PR \& Gault VA 2014 Lixisenatide improves recognition memory and exerts neuroprotective actions in high-fat fed mice. Peptides 61 38-47. (doi:10.1016/j.peptides.2014.08.014)

Li Y, Zheng X, Meng F \& Gong M 2016 Application of self-assembling peptide as drug carrier for extending the GLP-1 stability. International Journal of Clinical and Experimental Medicine 9 7828-7836.

Livak KJ \& Schmittgen TD 2001 Analysis of relative gene expression data using real-time quantitative PCR and the 2(-Delta C(T)) method. Methods 25 402-408. (doi:10.1006/meth.2001.1262)

Macdonald FR, Peel JE, Jones HB, Mayers RM, Westgate L, Whaley JM \& Poucher SM 2010 The novel sodium glucose transporter 2 inhibitor dapagliflozin sustains pancreatic function and preserves islet morphology in obese, diabetic rats. Diabetes Obesity and Metabolism 12 1004-1012. (doi:10.1111/j.14631326.2010.01291.x)

Madsen K, Knudsen LB, Agersø H, Nielsen PF, Thøgersen H, Wilken M \& Johansen NL 2007 Structure-activity and protraction relationship of long-acting glucagon-like peptide-1 derivatives: importance of fatty acid length, polarity, and bulkiness. Journal of Medicinal Chemistry $\mathbf{5 0}$ 6126-6132. (doi:10.1021/jm070861j)

Matthaei S, Bowering K, Rohwedder K, Sugg J, Parikh S, Johnsson E \& Study 05 Group 2015 Durability and tolerability of dapagliflozin over 52 weeks as add-on to metformin and sulphonlyurea in type 2 diabetes. Diabetes Obesity and Metabolism 17 1075-1084. (doi:10.1111/ dom.12543)

McClean PL, Parthsarathy V, Faivre E \& Hölscher C 2011 The diabetes drug liraglutide prevents degenerative processes in a mouse model of Alzheimer's disease. Journal of Neuroscience 31 6587-6594. (doi:10.1523/JNEUROSCI.0529-11.2011)

Merovci A, Mari A, Solis C, Xiong J, Daniele G, Chavez-Velazquez A, Tripathy D, Urban McCarthy S, Abdul-Ghani M \& DeFronzo RA 2015 Dapagliflozin lowers plasma glucose concentration and improves beta-cell function. Journal of Clinical Endocrinology and Metabolism 100 1927-1932. (doi:10.1210/jc.2014-3472)

Millar PJ, Pathak V, Moffett RC, Pathak NM, Bjourson AJ, O'Kane MJ, Flatt PR \& Gault VA 2016 Beneficial metabolic actions of a stable GIP agonist following pre-treatment with a SGLT2 inhibitor in high fat fed diabetic mice. Molecular and Cellular Endocrinology 420 37-45. (doi:10.1016/j.mce.2015.11.019)

Moffett RC, Vasu S, Thorens B, Drucker DJ \& Flatt PR 2014 Incretin receptor null mice reveal key role of GLP-1 but not GIP in pancreatic beta cell adaptation to pregnancy. PLoS ONE 9 e96863. (doi:10.1371/ journal.pone.0096863)
Moffett RC, Patterson S, Irwin N \& Flatt PR 2015 Positive effects of GLP-1 receptor activation with liraglutide on pancreatic islet morphology and metabolic control in C57BL/KsJ db/db mice with degenerative diabetes. Diabetes Metabolism Research and Reviews 31 248-255. (doi:10.1002/dmrr.2608)

Mudaliar S, Henry RR, Boden G, Smith S, Chalamandaris AG, Duchesne D, Iqbal N \& List J 2014 Changes in insulin sensitivity and insulin secretion with the sodium glucose cotransporter 2 inhibitor dapagliflozin. Diabetes Technology and Therapeutics 16 137-144. (doi:10.1089/dia.2013.0167)

Nagata T, Fukuzawa T, Takeda M, Fukazawa M, Mori T, Nihei T, Honda K, Suzuki Y \& Kawabe Y 2013 Tofogliflozin, a novel sodium-glucose co-transporter 2 inhibitor, improves renal and pancreatic function in $\mathrm{db} / \mathrm{db}$ mice. British Journal of Pharmacology 170 519-531. (doi:10.1111/bph.12269)

Parthsarathy V, McClean PL, Hölscher C, Taylor M, Tinker C, Jones G, Kolosov O, Salvati E, Gregori M, Masserini M, et al. 2013 A novel retro-inverso peptide inhibitor reduces amyloid deposition, oxidation and inflammation and stimulates neurogenesis in the APPswe/ PS1 $\triangle \mathrm{E} 9$ mouse model of Alzheimer's disease. PLOS ONE 8 e54769. (doi:10.1371/journal.pone.0054769)

Podrini C, Cambridge EL, Lelliott CJ, Carragher DM, Estabel J, Gerdin AK, Karp NA, Scudamore CL, Sanger Mouse Genetics Project, Ramirez-Solis R, et al. 2013 High-fat feeding rapidly induces obesity and lipid derangements in C57BL/6N mice. Mammalian Genome 24 240-251. (doi:10.1007/s00335-013-9456-0)

Porter WD, Flatt PR, Hölscher C \& Gault VA 2013 Liraglutide improves hippocampal synaptic plasticity associated with increased expression of Mash1 in ob/ob mice. International Journal of Obesity 37 678-684. (doi:10.1038/ijo.2012.91)

Rahmoune H, Thompson PW, Ward JM, Smith CD, Hong G \& Brown J 2005 Glucose transporters in human renal proximal tubular cells isolated from the urine of patients with non-insulin-dependent diabetes. Diabetes 54 3427-3434. (doi:10.2337/diabetes.54.12.3427)

Rani V, Deshmukh R, Jaswal P, Kumar P \& Bariwal J 2016 Alzheimer's disease: is this a brain specific diabetic condition? Physiology and Behavior 164 259-267. (doi:10.1016/j.physbeh.2016.05.041)

Renner S, Blutke A, Streckel E, Wanke R \& Wolf E 2016 Incretin actions and consequences of increin-based therapies: lessons from complementray animal models. Journal of Pathology 238 345-358. (doi:10.1002/path.4655)

Scheen AJ \& Paquot N 2014 Metabolic effects of SGLT2 inhibitors beyond increased glucosuria: a review of the clinical evidence. Diabetes and Metabolism 40 S4-S11. (doi:10.1016/S1262-3636(14)72689-8)

Schwasinger-Schmidt T, Robbins DC, Williams SJ, Noyikova L \& Stehno-Bittel L 2013 Long-term liraglutide treatment is associated with increased insulin content and secretion in beta cells, and a loss of alpha cells in ZDF rats. Pharmacological Research 76 58-66. (doi:10.1016/j.phrs.2013.07.005)

Srinivasan K, Viswanad B, Asrat L \& Ramarao KP 2005 Combination of high-fat diet-fed and low-dose streptozotocin-treated rat: a model for type 2 diabetes and pharmacological screening. Pharmacological Research 52 313-320. (doi:10.1016/j.phrs.2005.05.004)

Stranahan AM, Norman ED, Lee K, Cutler RG, Telljohann RS, Egan JM \& Mattson MP 2008a Diet-induced insulin resistance impairs hippocampal synaptic plasticity and cognition in middle-aged rats. Hippocampus 18 1085-1088. (doi:10.1002/hipo.20470)

Stranahan AM, Arumugam TV, Cutler RG, Lee K, Egan JM \& Mattson MP $2008 b$ Diabetes impairs hippocampal function through glucocorticoid-mediated effects on new and mature neurons. Nature Neuroscience 11 309-317. (doi:10.1038/nn2055)

Stranahan AM, Lee K, Pistell PJ, Nelson CM, Readal N, Miller MG, Spangler EL, Ingram DK \& Mattson MP 2008c Accelerated cognitive aging in diabetic rats is prevented by lowering corticosterone levels. Neurobiology of Learning and Memory 90 479-483. (doi:10.1016/j. nlm.2008.05.005) 
Timper K, Dalmas E, Dror E, Rütti S, Thienel C, Sauter NS, Bouzakri K, Bédat B, Pattou F \& Kerr-Conte J 2016 Glucose-dependent insulinotropic peptide stimulates glucagon-like peptide 1 production by pancreatic islets via interleukin 6, produced by $\alpha$ cells. Gastroenterology 151 165-179. (doi:10.1053/j.gastro.2016.03.003)

Tramutola A, Arena A, Cini C, Butterfield DA \& Barone E 2017 Modulation of GLP-1 signaling as a novel therapeutic approach in the treatment of Alzheimer's disease pathology. Expert Review of Neurotherapeutics 17 59-75. (doi:10.1080/14737175.2017.1246183)

Vasu S, Moffett RC, Thorens B \& Flatt PR 2014 Role of endogenous GLP-1 and GIP in beta cell compensatory responses to insulin resistance and cellular stress. PLOS ONE 9 e101005. (doi:10.1371/journal. pone.0101005)
Vivian EM 2015 Dapagliflozin: a new sodium-glucose cotransporter 2 inhibitor for treatment of type 2 diabetes. American Journal of HealthSystem Pharmacy 72 361-372. (doi:10.2146/ajhp140168)

Zaccardi F, Webb DR, Yates T \& Davies MJ 2016 Pathophysiology of type 1 and type 2 diabetes mellitus: a 90-year perspective. Postgraduate Medical Journal 92 63-69. (doi:10.1136/ postgradmedj-2015-133281)

Zambrowicz B, Ding ZM, Ogbaa I, Frazier K, Banks P, Turnage A, Freiman J, Smith M, Ruff D, Sands A, et al. 2013 Effects of LX4211, a dual SGLT1/SGLT2 inhibitor, plus sitaglitpin on postprandial active GLP-1 and glycaemic control in type 2 diabetes. Clinical Therapeutics 35 273-285. (doi:10.1016/j. clinthera.2013.01.010)

Received in final form 6 June 2017

Accepted 13 June 2017

Accepted Preprint published online 13 June 2017
๑) 2017 Society for Endocrinology Printed in Great Britain
Published by Bioscientifica Ltd. 